\title{
Foreword
}

\section{Olivier De Schutter}

In this dense and yet highly readable book, Elisabeth Bürgi Bonanomi discusses the rise of the concept of sustainable development as a principle of international law, and applies its requirements to the specific question of trade liberalisation for agricultural products. There are three reasons why both the inquiry and the conclusions should matter not just to scholars of international economic and environmental law, but also to all those with a concern for a fair and just globalization.

First, Elisabeth Bürgi's book makes a major contribution to promoting sustainable development as a legally binding principle, precise enough not only to guide the interpretation of international treaties, but also to influence the negotiation of such instruments. It has been more than 40 years since the concern for a sustainable use of natural resources and for an appropriate balance between development and environmental considerations have been referred to in international conferences: the Declaration on the Human Environment, adopted at the United Nations Conference on the Human Environment convened in Stockholm in June 1972, mentioned the need to exploit non-renewable raw materials 'as to guard against the danger of their future exhaustion and to ensure that benefits from such employment are shared by all mankind' (Principle 5), and Principles 6 to 10 of the Declaration mention the need to combine efforts in favour of the development of poor countries with environmental policy, stating that economic and social development and sound management of resources are mutually supportive. One of the outcomes of the Stockholm Conference was to establish the United Nations Environment Programme (UNEP) as a subsidiary organ of the UN General Assembly. The concept of sustainable development was soon put forward by UNEP in a Decision of its Governing Council adopted in 1975: 'Environmental management', it noted then, 'implies sustainable development of all countries, aimed at meeting basic human needs without transgressing the outer limits set to man's endeavours by the biosphere'. The concept was later built upon by the Brundtland Commission and the Rio Conference of 1992. 
Although there is a long history behind the concept of sustainable development, it has lacked hitherto a truly operational dimension: its ability to shape policies and to guide negotiations has remained limited, largely due to the fact that the trade-offs between its different components (economic, social and environmental) have not been addressed explicitly. The contribution of Elisabeth Bürgi in this regard is significant. Based on the work of Gehne, she proposes a framework that seeks to reconcile the competing interests that cohabit within the concept of sustainable development, offering an original - and, even more important, workable - methodology to accommodate them into a single, coherent approach.

For this reason alone, this book would be worth reading, and would deserve to be widely used and cited. Yet, Elisabeth Bürgi does more. She also applies her framework to the area of agriculture, asking in particular whether the Agreement of Agriculture could be further improved in order to serve the objective of sustainable development. This indeed is a domain in which the lack of alignment between different policies has been particularly remarkable - almost a paradigmatic case of inconsistent policy choices.

The second reason why this book by Elisabeth Bürgi is important is because of the policy failure that it documents. When the global food system was shaped initially, in the 1960s, it was designed to maximize efficiency gains and produce large volumes of commodities. The objective was explicitly to increase calorie availability, in the hope that supply would match and even exceed demand. According to their own standards, these policies were highly successful: increases in agricultural productivity consistently outstripped demographic growth during the period 19602000. But these gains went hand in hand with regional specialization in a relatively narrow range of products, a process encouraged by the growth of international trade in agriculture, which the Agreement on Agriculture included in 1994 among the Marrakech Agreements establishing the World Trade Organisation (WTO) further accelerated. The benefits of this push towards export-led agriculture were concentrated in the hands of large production units and landholders at the expense of smaller-scale producers and landless workers. This resulted in the growth of inequality in rural areas and a failure to address the root causes of poverty. The shift to monocultures itself, apparently a purely agronomic choice, in fact had important distributive consequences: it rewarded economies of scale and encouraged mechanization, thus improving labour productivity but also giving a premium to the largest landholders who were in a better position to achieve efficiency gains under this model. 
What we had, in sum, was a system that prioritized one objective efficiency gains through specialization, and thus improved productivity at the expense of all other, competing considerations: whereas increased opportunities to trade were seen as stimulating the growth of the agricultural sector (this explains why developing countries were keen to see agriculture included as part of the Uruguay round of trade negotiations in the first place), neither rural development or the reduction of rural poverty, nor the sustainable use of resources, were seriously considered in the process. Of course, the preamble of the Agreement establishing the WTO states that Members' 'relations in the field of trade and economic endeavour should be conducted with a view to raising standards of living, ensuring full employment and a large and steadily growing volume of real income and effective demand, and expanding the production of and trade in goods and services, while allowing for the optimal use of the world's resources in accordance with the objective of sustainable development, seeking both to protect and preserve the environment and to enhance the means for doing so in a manner consistent with their respective needs and concerns at different levels of economic development'. Elisabeth Bürgi is correct to emphasize the need to take seriously the promise contained in this statement. The reality, however, is that by insisting on a reform programme that would gradually lower the obstacles to trade and remove trade-distorting subsidies, the Agreement on Agriculture in fact led to the prioritization of efficiency gains over everything else.

The global food prices crisis of 2007-08 brought to light the fragility of the system that has been thus established. The worst hit by the crisis were low-income, food-deficit countries. This was of course paradoxical, for these countries are still largely agriculture-based: much of their GDP and much of their employment depend on that sector. Yet, because of the incentives provided by the global trading system and because of the pressure imposed on them under the structural adjustment of the 1980s and 1990s, these countries had largely been turned into raw commodityexporting economies by the end of the century. As these countries had neglected to invest in local production and food processing to feed their own communities, their food imports had increased in large proportions: they had moved to exporting more tropical agricultural products, mostly unprocessed, in order to import food commodities, often in processed form. This strategy was seen as viable as long as the prices of agricultural commodities were declining on international markets: indeed, the addiction of these countries to cheap food imports and the resulting lack of investment in food production to satisfy local needs were encouraged by massive overproduction in better-off exporting 
countries, stimulated by subsidies going to the largest agricultural producers in these countries, and ensuring access to cheap inputs to the food processing industry. It was further facilitated by the growth of international trade and investment and the corresponding increase of the role of large agribusiness corporations in the food systems.

It is this model that has failed, illustrating what is at the heart of Elisabeth Bürgi's thesis: that trade should not be seen as an end in itself, nor the expansion of international trade as desirable per se, but that trade is a means to an end - one we should define more clearly in order to ensure that it is not lost sight of in the course of negotiating around trade. Indeed, the 2007-08 crisis provoked a sober re-examination of the approaches to hunger and malnutrition that had prevailed in the past. It led many governments to acknowledge that underlying the immediate causes of the agricultural commodity price increases were a number of structural factors that could only be addressed through improved international cooperation. The global food price crisis was, ultimately, a failure of global governance. Many came to the conclusion, in particular, that the trade regime - as institutionalized since 1994 under the umbrella of the World Trade Organisation (WTO) - was ill-suited to what was required to achieve real food security, creating the wrong set of incentives for many developing, net-food-importing countries.

Instead, in order for States to successfully implement national rights to food strategies, it had by then become clear that two conditions had to be fulfilled. First, agricultural policies should achieve a balance between the support going to export-led agriculture and the support to small-scale food producers producing for themselves, their families and their communities. Supporting the local production of food crops is not only a way to reduce the dependency of the country on food imports, and thus the vulnerability of the country to price shocks on international markets; it is also a means to raise incomes in rural areas, where the majority of the extremely poor still often reside. Second, jobs must be created in the industry and services sectors, in order to absorb the excess workforce migrating from the rural areas. Ideally thus, what is required is a complementarity between these different sectors (agriculture, industry and services): small-scale, family agriculture should be supported in order to reduce rural poverty; but in addition, in what Irma Adelman famously called 'agriculture-led industrialization', it may both ensure a market for the local producers of manufactured goods and serviceproviders, and should allow the growth of a food processing industry, and associated services, which contribute to the strengthening of local food systems. 
This largely explains why the reform of the Committee of World Security was seen as a priority following the crisis. Initially established in 1974 after the first World Food Conference as an intergovernmental committee within the United Nations Food and Agriculture Organization (FAO), the CFS was reformed in 2009 with the aim of becoming 'the foremost inclusive international and intergovernmental platform for a broad range of committed stakeholders to work together in a coordinated manner and in support of country-led processes towards the elimination of hunger and ensuring food security and nutrition for all human beings'. As a result of the reform, it now includes as members all governments, who are encouraged to participate at Ministerial level, 'insofar as possible representing a common, inter-ministerial governmental position'. Participants in the mechanism - who have the same rights as members except with respect to voting and decision taking - include the representatives of UN agencies and bodies with a specific mandate in the field of food security and nutrition and representatives of other relevant UN system bodies whose overall work is related to attaining food security, nutrition and the right to food, such as the Special Rapporteur on the Right to Food, the Office of the High Commissioner on Human Rights, the World Health Organization, United Nations Children's Fund (Unicef), United Nations Development Programme (UNDP), and the Standing Committee on Nutrition (SCN); civil society and non-governmental organizations; international agricultural research systems; the World Bank, the International Monetary Fund, regional development banks and the WTO; and the private sector and philanthropic foundations active in the area of food security.

The CFS is, so far, the most ambitious attempt to overcome the fragmentation of global governance in the areas of food and agriculture. It is expected to provide a platform for discussion and coordination to strengthen collaborative action among its members and participants, including to "promote greater policy convergence and coordination ... through the development of international strategies and voluntary guidelines on food security and nutrition on the basis of best practices, lessons learned from local experience, inputs received from the national and regional levels, and expert advice and opinions from different stakeholders', and to provide support and advice to countries and regions. It should also promote accountability by 'developing an innovative mechanism, including the definition of common indicators, to monitor progress towards these agreed upon objectives and actions'; and implement a Global Strategic Framework for Food Security and Nutrition, conceived as a flexible, 'rolling' document that can be regularly updated on the 
basis of new information and new priorities, 'in order to improve coordination and guide synchronized action by a wide range of stakeholders'.

This, therefore, is a third reason why this volume by Elisabeth Bürgi is both important and timely: the area of food and agriculture provides what is by far the most advanced attempt to overcome the fragmentation of global governance, by moving instead towards a single, coordinated strategy across different policy areas, falling under the mandates of different international agencies and involving different constituencies and epistemic communities, each offering a different framing of the problem to be addressed.

Sustainable development, now made fully operational thanks to the contribution of Elisabeth Bürgi, can support policy reforms that will improve global governance, thus ensuring that the trade regime is shaped to support the policy objectives that it is meant to serve. The area of food and agriculture is in many ways a case study of a lack of consistency across policy areas. It is now high time to overcome this failure. I have no doubt that this volume represents a major contribution towards this end.

Professor Olivier De Schutter

Former United Nations Special Rapporteur on the right to food (2008-2014) Member of the UN Committee on Economic, Social and Cultural Rights January 2015 